\title{
CLINICAL ANALYSIS OF ASSOCIATION OF CYSTATIN C AND ATRIAL FIBRILLATION
}

\author{
Ping Liu, Shujian Sui, Dongling Xu
}

Some studies have disclosed atrial fibrillation (AF) is associated with inflammation. Cystatin $\mathrm{C}$ is not only inflammatory markers but also an independent predictor of cardiovascular events.

Aim. We sought to investigate the relationship between serum levels of cystatin $C$ and the occurrence and development of AF.

Material and methods. 235 paroxysmal and persistent AF (AF1 group) and 254 permanent AF (AF2 group) patients in AF group and 221 healthy people in control group were prospectively measured for cystatin $C$, other inflammatory markers, biochemical indicators, left atrial diameter (LAD), left ventricular diameter (LVD) and left ventricular ejection fraction (LVEF).

Results. (1) Compared with control and AF1 groups, AF2 group had higher values of cystatin $C$, high sensitivity $C$ reactive protein (hSCRP), LAD and LVD whereas lower values of LVEF $(P<0.05)$. (2) After adjust for age, gender and body mass index (BMI), correlation analysis showed that serum level of cystatin $\mathrm{C}$ was closely related to hsCRP, LAD, systolic blood pressure (SBP) and creatinine, the correlation coefficient were respectively $0,614,0,520,0,463$ and 0,538 (all $P<0,01$ ), but negatively associated with $\operatorname{LVEF}(r=-0,356, P=0,012)$ in AF group. (3) Multivariate regression analysis showed the hSCRP, cystatin $C, L A D$ and LVEF entered finally into the regression equation (cystatin C, OR: $3.25,95 \% \mathrm{Cl}: 1.05-10.17, \mathrm{P}=0,008$ )

Conclusion. The serum levels of cystatin $C$ has significant correlation with $A F$, which indicates cystatin $\mathrm{C}$ may play an important role in the process of $\mathrm{AF}$ development.

Russ J Cardiol 2014, 7 (111), Engl.: 17-22
Key words: cystatin C, atrial fibrillation, inflammation, inflammatory markers.

Department of Cardiology, the Second Hospital of Shandong University, Jinan Shandong 250033, China

Corresponding author. Ping Liu, MD, PhD, Department of Cardiology, the Second Hospital of Shandong University, No.247, Beiyuan Road, Jinan, Shandong 250033 P. R. China, Tel: +86-531-85875465, Fax+86-531-88962544, e-mail: Iping@sdu. edu.cn

$\mathrm{AF}$ - Atrial fibrillation, BUN - Blood urea nitrogen, BMI - Body mass index, ECG Electrocardiogram, EDTA - Ethylenediamine tetraacetic acid, FBG - Fasting blood glucose, GFR - Glomerular filtration rate, hsCRP - High sensitivity C reactive protein, HDL-C - High-density lipoprotein cholesterol, LAD - Left atrial diameter, LVD - Left ventricular diameter, LVEF - Left ventricular ejection fraction, LDL-C Low-density lipoprotein cholesterol, $\mathrm{Cr}$ - Serum creatinine, SBP - Systolic blood pressure, DBP - Diastolic blood pressure, TC - Total cholesterol, TG Triglycerides, WBC - White blood (cell) count.

Received July 23, 2014

Revision received July 24, 2014

Accepted July 30, 2014.

\section{КЛИНИЧЕСКИЙ АНАЛИЗ АССОЦИАЦИИ ЦИСТАТИНА С И ФИБРИЛЛЯЦИИ ПРЕДСЕРДИЙ}

Ping Liu, Shujian Sui, Dongling Xu

В некоторых исследованиях было выявлено, что фибрилляция предсердий (ФП) связана с воспалением. Цистатин С является не только воспалительным маркером, но и независимым предиктором сердечно-сосудистых событий.

Цель. Мы попытались выяснить отношения между уровнем цистатина С в сыворотке крови и возникновением и развитием ФП.

Материал и методы. 235 пациента с пароксизмальной и персистирующей ФП (ФП1 группа), 254 пациента с постоянной ФП (ФП2 группа) и 221 здоровых людей в контрольной группе были под наблюдением для измерения цистатина C, других воспалительных маркеров, биохимических показателей, диаметра левого предсердия (LAD), диаметра левого желудочка (LVD) и фракции выброса левого желудочка (ФВ ЛЖ).

Результаты. (1) В сравнении с группой контроля, группы ФП1 и ФП2 имели более высокие значения уровня цистатина C, высокую чувствительность C реактивного белка (hsCRP), LAD и LVD в тоже время - низкие значения ФВ ЛЖ $(\mathrm{P}<0,05)$. (2) После ранжирования по возрасту, полу и индексу массы тела (ИМТ), корреляционный анализ показал, что сывороточный уровень цистатина C тесно связан с hsCRP LAD, систолическим артериальным давле-

\section{Introduction}

Atrial fibrillation (AF) is the most common cardiac arrhythmia and increases in prevalence with aging [1-3]. It has become one of the leading causes for hospitalized patients with AF because AF may induce stroke, heart failure and increase case fatality $[1,2,4]$. Unfortunately, its fundamental pathological mechanisms are not fully clear. Recent evidence is accumulating that AF may be closely interrelated with inflammation and inflammatory biomarkers $[2,4-6]$. Some studies confirmed that diverse inflammatory factors participate in pathogenesis and development of AF [6-8]. нием (САД) и креатинином, коэффициенты корреляции были, соответственно, 0,614, 0,520, 0,463 and 0,538 ( $\mathrm{P}<0,01)$, но отрицательно ассоциированы с ФВ ЛЖ ( $r=-0,356, \mathrm{P}=0,012)$ в группе с ФП. (3) Многофакторный регрессионный анализ показал, что hsCRP, цистатин C, LAD и ФВ ЛЖ в конечном счете входят в уравнение регрессии (цистатин C, OR: $3.25,95 \% \mathrm{Cl}: 1.05$ $10.17, \mathrm{P}=0,008)$.

Заключение. Уровень цистатина С в сыворотке крови имеет значимые корреляции с ФП, которая указывает на то, что цистатин С, может играть важную роль в процессе развития ФП.

Российский кардиологический журнал 2014, 7 (111), Англ.: 17-22

Ключевые слова: цистатин С, фибрилляция предсердий, воспаление, маркеры воспаления.

Department of Cardiology, the Second Hospital of Shandong University, Jinan, Shandong 250033, Китай.

Cysteine protease inhibitors- $\mathrm{C}$ (cystatin $\mathrm{C}$ ) is a member of protease inhibitor superfamily. cystatin $\mathrm{C}$ is not only a relatively more sensitive indicator of evaluating renal function than creatinine, but also an independent and strong predictor of cardiovascular events $[7,9]$. Recently studies find cystatin $\mathrm{C}$ is closely related to the inflammatory process or other inflammation factors $[7,10]$. However, it remains challenged whether or not there is correlation between cystatin $\mathrm{C}$ and $\mathrm{AF}$. In this study, the correlation between cystatin $\mathrm{C}$ and $\mathrm{AF}$ was investigated and its possible pathogenesis was preliminarily discussed and elucidated. 


\section{Material and methods}

\section{Patients}

A total of 710 consecutively hospitalized patients with AF (assigned to group AF) were prospectively recruited between June 2008 and December 2010 from the Second Hospital of Shandong University and Qilu Hospital of Shandong University, which included 235 cases of paroxysmal and persistent AF (placed to group AF1), 121 males and 114 females with mean age of $67,42 \pm 12,29$ years old. There were 254 cases of permanent AF (put to group AF2), 129 males and 125 females, averaged $(68,15 \pm 11,52)$ years old. All cases of AF diagnosed were verified by medical history, physical examination, electrocardiogram or dynamic electrocardiogram. The control group had 221 cases of adults after health examination in the Second Hospital of Shandong University, selected from outpatients without diseases or with minor illnesses from cardiac or other departments following the same exclusion criteria. Of which, there were 113 male cases, 108 female cases with a mean age of $66,70 \pm 12,18$ years old. Electrocardiogram showed sinus rhythm in control group. There were not any statistically significant differences $(\mathrm{P}>0,05)$ but comparability in comparison with age, sex and etiological composition among the three groups.

AF was defined and classified according to the management of atrial fibrillation of the European Society of Cardiology (ESC, 2010 edition) [11]. Paroxysmal AF is self-terminating usually within 48 hours, and may continue for up to 7 days. Persistent AF is present when an AF episode either lasts longer than 7 days or requires termination by cardioversion, either with drugs or by direct current cardioversion. Permanent AF is said to exist when the presence of the arrhythmia is accepted by the patient (and physician). Patients with any of the following conditions were excluded from the study: infectious diseases, malignant tumors; hyperthyroidism; hypokalemia, hypomagnesemia, hypocalcemia and acidosis; pneumonia and pulmonary embolism; moderate and severe anemia; intracranial hemorrhage; liver and renal abnormal function and other organs dysfunction; immune system and endocrine metabolic diseases; pregnant women and breastfeeding women; on some medicines such as statins and angiotensin-converting enzyme-inhibitors and/or angiotensin II receptor blockers. This research was conducted in accordance with the ethical principles stated in the "Declaration of Helsinki". The study protocol and written informed consent were approved by the Ethics Committee of Clinical Research, the Secondary Hospital of Shandong University.

\section{Methods}

Peripheral vein blood were obtained from all participants early in the day after a $12 \mathrm{~h}$ fast, immediately transferred into a glass tube containing disodium ethylenediamine tetraacetic acid (EDTA), and centrifuged for $10 \mathrm{~min}$ at
$3000 \mathrm{round} / \mathrm{min}$, separated in aliquots and then stored at $-80{ }^{\circ} \mathrm{C}$. Cystatin $\mathrm{C}$ and hsCRP were respectively measured by means of a particle-enhanced turbidimetric immunoassay with commercial kits (Serum cystatin C, Beijing Leadman Biochemistry Co., Ltd. Beijing, China; hsCRP, Diagnostic System Laboratory Inc, Webster, TX, USA). Its normal reference value is $0-3 \mathrm{mg} / \mathrm{L}$.

Fasting blood glucose, total cholesterol, low-density lipoprotein cholesterol, high-density lipoprotein cholesterol, triglycerides, blood urea nitrogen and serum creatinine were measured in automatic biochemical analyzer (Hitachi 7600, Tokyo, Japan) with enzymic method in all subjects. Blood routine was tested in a Sysmex XE-2100 hematology analyzer (Sysmex corporation, Kobe, Japan). Every participant received the test of a 12-lead MAC1200 electrocardiogram system (GE Healthcare, Milwaukee, WI, USA). Left atrium diameter (LAD), left ventricular diameter (LVD) and left vetricular ejection fraction (LVEF) were recorded using a Philips iE33 ultrasonocardiograph (Philips Medical Systems, Bothell, WA, USA).

\section{Statistical treatment}

Continuous variables were expressed as mean \pm SD and categorical variables were presented as percentages. Continuous variables were compared using one-way ANOVA, and categorical variables were compared with chi-square test. The relationship between variables was evaluated by significance calculation of partial correlation analysis after adjusting classical risk factors (age, sex and body weight). The overall influence of selected risk factors on the AF was assessed using binary logistic regression. Predictors of AF were determined by the multivariate regression analysis. The association between variables and the occurrence of AF was represented by odds ratio (OR) and their accompanying $95 \%$ confidence interval $(95 \%$ CI). SPSS 17.0 (SPSS Inc., Chicago, IL, USA) was used for all calculations. $\mathrm{P}<0,05$ was considered significant.

\section{Results \\ Comparison of baseline data between AF and control groups}

Baseline characteristics are shown in Table1. Compared with control group, AF1 and AF2 groups did not have statistical significance in age, gender, triglycerides, total cholesterol and high-density lipoprotein cholesterol $(\mathrm{P}>0,05)$, but had higher values of $\mathrm{BM}$, systolic blood pressure, fasting blood glucose and serum creatinine $(\mathrm{P}<0,05$ or $\mathrm{P}<0,01)$. Values of blood urea nitrogen and low-density lipoprotein cholesterol were significantly higher whereas those of diastolic blood pressure were significantly lower in group AF2 than in control group. While there were not any significant differences in the values of blood pressure, blood urea nitrogen and lowdensity lipoprotein cholesterol between group AF1 and control group $(\mathrm{P}>0,05)$. Furthermore there were not any 
Table 1

\section{Comparison of baseline data between atrial fibrillation and control groups}

\begin{tabular}{|c|c|c|c|}
\hline Variables & control group & group AF1 (paroxysmal and persistent) & group AF2 (permanent) \\
\hline Number of cases & 221 & 235 & 254 \\
\hline Age (year) & $66,70 \pm 12,18$ & $67,42 \pm 12,29$ & $68,15 \pm 11,52$ \\
\hline Body mass index $\left(\mathrm{kg} / \mathrm{m}^{2}\right)$ & $26,31 \pm 4,38$ & $28,41 \pm 4,77^{*}$ & $28,96 \pm 5,08^{*}$ \\
\hline Systolic blood pressure $(\mathrm{mmHg})$ & $132,34 \pm 13,26$ & $143,60 \pm 14,29^{*}$ & $144,21 \pm 15,75^{\star}$ \\
\hline Diastolic blood pressure (mmHg) & $82,91 \pm 10,68$ & $79,65 \pm 11,32$ & $78,81 \pm 11,06^{*}$ \\
\hline Fasting blood glucose $(\mathrm{mmol} / \mathrm{l})$ & $5,86 \pm 1,24$ & $6,25 \pm 2,20^{*}$ & $6,35 \pm 2,44^{\star \star}$ \\
\hline Blood urea nitrogen $(\mathrm{mmol} / \mathrm{l})$ & $5,94 \pm 2,27$ & $6,31 \pm 3,08$ & $6,58 \pm 3,13^{\star *}$ \\
\hline Creatinine (umol/l) & $60,78 \pm 12,56$ & $87,61 \pm 25,80^{*}$ & $88,23 \pm 26,40^{\star *}$ \\
\hline Triglycerides (mol/l) & $1,18 \pm 0,54$ & $1,21 \pm 0,48$ & $1,24 \pm 0,59$ \\
\hline Total cholesterol (mol/l) & $4,45 \pm 0,86$ & $4,37 \pm 0,78$ & $4,50 \pm 0,71$ \\
\hline High-density lipoprotein (mol/l) & $1,32 \pm 0,34$ & $1,26 \pm 0,29$ & $1,21 \pm 0,31$ \\
\hline Low-density lipoprotein (mol/l) & $2,59 \pm 0,63$ & $2,63 \pm 0,58$ & $2,70 \pm 0,68^{*}$ \\
\hline
\end{tabular}

Compared with control group: ${ }^{*} P<0.05,{ }^{* *} P<0.01$

Table 2

\section{Comparison of inflammatory indicators between AF and control groups}

\begin{tabular}{l|l|l|l}
\hline Variables & control group & group AF1 & group AF2 \\
\hline White blood cell count $\left(\times 10^{9} / \mathrm{L}\right)$ & $5,88 \pm 1,85$ & $6,09 \pm 1,92$ & $6,13 \pm 2,04$ \\
\hline $\operatorname{hsCRP}(\mathrm{mg} / \mathrm{l})$ & $1,27 \pm 1,08$ & $2,75 \pm 1,17^{\star *}$ & $3,91 \pm 1,24^{\star * \#}$ \\
\hline cystatin C $(\mathrm{mg} / \mathrm{l})$ & $0,84 \pm 0,16$ & $1,06 \pm 0,29^{*}$ & $1,35 \pm 0,42^{\star *}$
\end{tabular}

Abbreviations: $\mathrm{AF}$ - atrial fibrillation, hsCRP - high sensitivity $\mathrm{C}$ reactive protein. Compared with control group, ${ }^{\star} P<0.05,{ }^{\star \star} P<0.01 ; \mathrm{Compared}$ with $\mathrm{AF} 1 \mathrm{group},{ }^{\sharp} P<0.05$ \#\# $P<0.01$

Table 3

Comparison of ultrasound parameters of left heart between AF and control groups

\begin{tabular}{|c|c|c|c|}
\hline Variables & control group & group AF1 & group AF2 \\
\hline left atrial diameter ( $\mathrm{mm}$ ) & $33,67 \pm 3,39$ & $43,56 \pm 10,64^{* *}$ & $47,10 \pm 11,72^{\star \star *}$ \\
\hline Left ventricular diameter (mm) & $49,50 \pm 7,34$ & $52,64 \pm 11,30^{\star}$ & $54,15 \pm 11,36^{\star \star *}$ \\
\hline Left ventricular ejection fraction (\%) & $54,83 \pm 8,51$ & $50,08 \pm 10,52^{*}$ & $47,36 \pm 12,14^{\star * \#}$ \\
\hline
\end{tabular}

Abbreviation: AF - atrial fibrillation, Compared with control group, ${ }^{\star} P<0.05,{ }^{* \star} P<0.01$; Compared with AF1 group, ${ }^{\#} P<0.05$, ${ }^{\# \#} P<0.01$

statistical differences in baseline datum between group AF1 and group AF2 (all $\mathrm{P}>0,05)$.

\section{Comparison of inflammatory indicators between AF and} control groups

As shown in Table 2, white blood cell counts showed no any significant difference $(\mathrm{P}>0,05)$ whereas there were significant difference in the values of cystatin $\mathrm{C}$ and hsCRP among these groups ( $\mathrm{P}<0,05$ or $\mathrm{P}<0,01)$. Compared with control group, AF1 and AF2 groups had higher values of cystatin $\mathrm{C}$ and hsCRP $(\mathrm{P}<0,05$ or $\mathrm{P}<0,01)$. Furthermore group AF2 had higher values of cystatin $C$ and hsCRP than those in group AF1 $(\mathrm{P}<0,05$ or $\mathrm{P}<0,01)$.

\section{Comparison of echocardiogram parameters between AF} and control groups

As outlined in Table 3, Echocardiogram showed AF1 and AF2 groups had higher values of left atrial diameter and left ventricular diameter but lower values of left ventricular ejection fraction than those of control group

Table 4

\section{Analysis for correlation between cystatin C and high risk factors of atrial fibrillation}

\begin{tabular}{|l|l|l|}
\hline Variables & $r$ & $P$ \\
\hline High sensitivity C reactive protein & 0,614 & 0,000 \\
\hline Left atrial diameter & 0,520 & 0,000 \\
\hline Left ventricular diameter & 0,247 & 0,043 \\
\hline Left ventricular ejection fraction & $-0,356$ & 0,012 \\
\hline Systolic blood pressure, & 0,463 & 0,005 \\
\hline Fasting blood glucose & 0,219 & 0,047 \\
\hline Serum creatinine & 0,528 & 0,008 \\
\hline Body mass index & 0,187 & 0,054 \\
\hline Low-density lipoprotein cholesterol & 0,165 & 0,039 \\
\hline
\end{tabular}

$(\mathrm{P}<0,05$ or $\mathrm{P}<0,01)$. Compared with group $\mathrm{AF} 1$, group AF2 had higher values of left atrial diameter and left ventricular diameter but lower values of left ventricular ejection fraction $(\mathrm{P}<0,05$ or $\mathrm{P}<0,01)$. 
Multiple logistic regression analysis of predictive factors for atrial fibrilation

\begin{tabular}{|l|l|l|l|l|}
\hline Variables & $\beta$ & SE & OR & $P$ \\
\hline High sensitivity C reactive protein & 0,72 & 2,89 & 3,74 & 0,014 \\
\hline Cystatin C & 0,61 & 2,36 & 3,25 & 0,008 \\
\hline Left atrial diameter & 0,35 & 1,14 & 1,86 & $1,17-13,84$ \\
\hline Systolic blood pressure & 0,59 & 0,90 & 1,79 & 0,036 \\
\hline Left ventricular ejection fraction & 0,55 & 0,84 & 1,27 & 0,005 \\
\hline
\end{tabular}

Analysis for correlation between cystatin $\mathrm{C}$ and high risk factors of $\mathrm{AF}$

As demonstrated in Table 4, after adjusting age, gender and body weight, cystatin $\mathrm{C}$ was closely related to hsCRP, left atrial diameter, systolic blood pressure and serum creatinine, and their correlation coefficient respectively were $0,614,0,520,0,463$ and 0,528 (all $\mathrm{P}<0,01$ ) whereas cystatin $\mathrm{C}$ was inversely related to left ventricular ejection fraction $(\mathrm{r}=-0,356, \mathrm{P}=0,012)$.

\section{Multivariate Analysis of AF risk factors}

As presented in Table 5, all selected variables from AF and control groups were analyzed by stepwise regression analysis and the related indicators were picked out. Finally, hsCRP, cystatin C, left atrial diameter, systolic blood pressure and left ventricular ejection fraction by turns entered the regression equation, showed in Table 5, hsCRP (OR: 3.74; 95\% CI: 1.17-13.84; $\mathrm{P}=0,014$ ), cystatin C (OR: 3.25; 95\% CI: $1.05-10.17 ; \mathrm{P}=0,008)$, left atrial diameter (OR: 1.86; 95\% CI: $0.92-5.64 ; \mathrm{P}=0,036$ ), systolic blood pressure (OR: 1.79; 95\% CI: 1.07-4.38; $\mathrm{P}=0,005)$ and left ventricular ejection fraction (OR: 1.27; 95\% CI: 0.82-3.08; $\mathrm{P}=0,044)$ included respectively.

\section{Discussion}

Cystatin $\mathrm{C}$ is a cysteine protease inhibitor with a molecular weight of $13 \mathrm{kD}$, synthesized in all nucleated cells at a constant rate. It is present in an unglycosylated protein form and is ubiquitous in animal and plant tissue. It participate in proteolytic regulation between the interior and the exterior of the cell $[7,12]$. Due to its free filtration in the glomerulus with nearly complete reabsorption and catabolism in the proximal tubule, and lack of tubular secretion, serum cystatin $\mathrm{C}$ concentrations are closely related to the glomerular filtration rate (GFR) reflecting renal function $[7,9,12]$. So cystatin $\mathrm{C}$ is thought to be a specific, accurate and more sensitive marker than creatinine clearance rate.

In recent years, a large number of studies have confirmed that cystatin $\mathrm{C}$ is likely to be an independent risk factor of cardiovascular disease [7,12]. The close relationship between cystatin $\mathrm{C}$ and cardiovascular disease is not only attributed to kidney function but is also thought to be mediated by inflammatory mechanism $[7,13,14]$. The unique association of AF with renal dysfunction could be explained by the fact that $\mathrm{AF}$ and renal dysfunction share a number of risk factors [15]. Although mechanical stress on atrium due to volume overload could be the mediating factor that leads to development of $\mathrm{AF}$ in patients with renal dysfunction, this does not explain the development of AF in earlier phases of renal dysfunction. In this situation, some researches make the beneficial attempt to these aspects $[13,14]$. Both the ARIC Study [13] and the Heart and Soul Study [14] only demonstrated the association between $\mathrm{AF}$ and renal function estimated by urinary albuminto-creatinine ratio (ACR) and cystatin C-based glomerular filtration rate (eGFRcys) rather than cystatin C itself. The Malmö Diet and Cancer study [9] only provide evidence that natriuretic peptides and CRP instead of cystatin $\mathrm{C}$ improve prediction of incident heart failure and $\mathrm{AF}$ in the general population in addition to conventional risk factors. However, these studies $[9,13,14]$ on cystatin $\mathrm{C}$ and $\mathrm{AF}$ are not discussed at all.

One possible mechanism for a higher prevalence of AF in early stages of renal insufficiency could be explained by inflammation [15]. In this study, as an indicator, only cystatin $\mathrm{C}$ among biochemical indicators (such as creatinine and blood urea nitrogen) refleting renal function in multivariate analysis had strong connection with AF. It is explained by the fact that cystatin $\mathrm{C}$ is more sensitive than other markers as a measure of renal function and is an inflammatory factor. Some researches also disclosed that cystatin $\mathrm{C}$ is a more reliable marker of renal function compared to creatinine or estimated GFR as it is less affected by age, gender, physical activity, diet and muscle mass, and ethnicity [9].

Many researchers have ascertained that cystatin $\mathrm{C}$ has a linear positive correlation with a variety of inflammatory cytokines such as hsCRP and reflects the severity of inflammatory activity, independent of renal function [12]. Cystatin $\mathrm{C}$ and its fragments may also affect the phagocytic and chemotactic functions of granulocytes and participate in the inflammatory process $[9,12]$. In atrial tissue of the patients with atrial fibrillation, inflammation results in inflammatory cell infiltration, oxidative stress and damage, this is followed by repair of the local tissue damage by fibrous tissue. As a result of this pathological process, atrial remodeling ensues [6-8]. It is worth mentioning that Targoński et al. found that the serum concentration of hsCRP is closely, positively correlated with the diameter size of left atrium [16]. The result of this study was consistent with Targoński's conclusion and showed that 
the serum concentration of cystatin $\mathrm{C}$ also coincided with left atrial diameter.

This study confirmed that atrial fibrillation groups had higher values of cystatin C, hsCRP and left atrial diameter than those in the control group. Furthermore, persistent atrial fibrillation group had significantly higher values of cystatin C, hsCRP and left atrial diameter than those in paroxysmal AF and control groups. At the same time, correlation analysis showed that cystatin $\mathrm{C}$ is closely related to hsCRP and left atrial diameter of patients with atrial fibrillation. Therefore it follows that the inflammatory cytokines such as cystatin $\mathrm{C}$ and hsCRP should modulate process of inflammatory, participate in the hypertrophic degeneration of atrial muscle fiber, induce atrial structural abnormalities in patients with atrial fibrillation and thus lead to atrial electrical remodeling [6-8]. Inflammation is closely associated to atrial fibrillation [6] and may be the important medium which links atrial fibrillation with known risk factors (such as high blood pressure and obesity, etc.) responsible for the development of atrial fibrillation $[1,3,17]$. Even the atrial pathoanatomy in lone atrial fibrillation showed inflammatory infiltration, muscle cell necrosis and fibrosis [1,17]. Modern research has confirmed that chronic inflammation has arrhythmogenic effect giving rise to the development of AF in susceptible populations. Inflammatory markers could be the result of atrial fibrillation rather than the cause of atrial fibrillation [18]. Conen et al. found that a rise the augment of hsCRP increased the risk of AF by $31 \%$ in the elderly [18]. In this study, monofactorial analysis showed that the serum levels of hsCRP and cystatin $\mathrm{C}$ in 2 atrial fibrillation groups were higher than those in control group, and they were closely related to each other. Multifactor analysis showed that both cystatin $\mathrm{C}$ and hsCRP, entered in the regression equation, had higher OR values (3.41 and 3.76, respectively). It was demonstrated that atrial fibrillation is closely associated with inflammation regardless of the duration of atrial fibrillation. However, this study showed no significant relationship between white blood cell count and risk of incident atrial fibrillation, which differs from the result of the Framingham Heart Study [19].

Cystatin $\mathrm{C}$ is not only an independent risk marker of predicting cardiovascular disease but also is an independent risk factor of MetS [7]. As mentioned above, cystatin C was not only related to inflammation but also was associated with the risk factors of atrial fibrillation which are also the components of metabolic syndrome. The risk of developing AF in patients with metabolic syndrome increased by $88 \%$, compared to those without metabolic syndrome. ${ }^{3}$ Atrial fibrillation and metabolic syndrome share common risk factors: obesity, hypertension, hyperglycemia and hyperlipidemia. The patients with higher level of cystatin $\mathrm{C}$ have higher metabolic state: higher body mass index, blood pressure, blood sugar and lipid levels [12]. Researches have shown that cystatin $\mathrm{C}$ is closely related to the metabolic syndrome [3,7]. Insulin resistance is not only the pathogenesis of metabolic syndrome but also may be the pathological process that connect cystatin $\mathrm{C}$ with metabolic syndrome [7,20]. Presumably, from another perspective, atrial filbrallation and the metabolic syndrome may have a common pathological relationship mediated by inflammtory biomakers such as cystatin $\mathrm{C}$. This study confirmed that body mass index, systolic blood pressure, fasting blood glucose and low-density lipoprotein cholesterol in AF groups, especially in permanent atrial fibrillation group (group AF2), were higher than those in the control group. Blood pressure is the most common risk factor of atrial fibrillation; moreover systolic blood pressure being the better predictor of atrial fibrillation than diastolic blood pressure [3]. This study also revealed that systolic blood pressure closely correlated to cystatin $\mathrm{C}$ as showed in the univariate analyse. Linssen, et al. pointed out that AF facilitate the progression of heart failure in several ways. Due to rapid heart rates, an irregular ventricular rhythm, loss of atrioventricular synchrony, and an increase in mitral and tricuspid regurgitation, AF may further decrease cardiac output and aggravate heart failure [21]. As shown in this study, left ventricular ejection fraction was also independently aligned with AF. Some studies have validated that obesity is an independent risk factor for predicting atrial fibrillation [3]. But this study showed that body mass index did not enter the regression equation in the multivariate analysis.

\section{Study limitations}

There were several limitations in this study. Our sample size, although small, was sufficient to diaplay differences between the control group and the group AF, however further studies with larger scale of cohorts are needed to confirmed these results. Additionally, some inflammatory indicators such as interleukin-6 and tumor necrosis factor $-\alpha$ were not applied in this study. Although these indicators maybe do not affect the conclusion of this study, which possibly made an impact on the estimate for action degree of hsCRP and cystatin $\mathrm{C}$ in this study. Furthermore, the relationship between cystatin $\mathrm{C}$ and atrial fibrillation was not verified by pathological and molecular biological methods. Finally, we did not progressively group the patients with paroxysmal and persistent atrial fibrillation into two parts according to AF duration.

\section{Conclusion}

In summary, as a new inflammatory factor, cystatin $\mathrm{C}$ is intimately associated with atrial fibrillation and may play an important role in the occurrence and development of atrial fibrillation. However, the specific relationship and precise mechanism between cystatin $\mathrm{C}$ and atrial fibrillation will need to be verified by a lot of further basic and clinical study. 


\section{References}

1. Ozaydin M. Atrial fibrillation and inflammation. World J Cardiol 2010;2 (8): 243-50.

2. Aldhoon B, Melenovský V, Peichl P, Kautzner J. New insights into mechanisms of atrial fibrillation. Physiol Res 2010; 59 (1):1-12.

3. Conen D, Osswald S, Albert CM. Epidemiology of atrial fibrillation. Swiss Med Wkly 2009; 139 (25-26):346-52.

4. Hagiwara N. Inflammation and atrial fibrillation. Circ J 2010;74 (2): 246-7.

5. Guo Y, Lip GY, Apostolakis S. Inflammation in atrial fibrillation. J Am Coll Cardiol 2012; 60 (22):2263-2270.

6. Smith JG, Newton-Cheh C, Almgren P, et al. Assessment of conventional cardiovascular risk factors and multiple biomarkers for the prediction of incident heart failure and atrial fibrillation. J Am Coll Cardiol 2010;56 (21): 1712-9.

7. Lee SH, Park SA, Ko SH, et al. Insulin resistance and inflammation may have an additional role in the link between cystatin $\mathrm{C}$ and cardiovascular disease in type 2 diabetes mellitus patients. Metabolism 2010;59 (2): 241-6.

8. Hadi HA, Alsheikh-Ali AA, Mahmeed WA, et al. Inflammatory cytokines and atrial fibrillation: current and prospective views. J Inflamm Res 2010;3:75-97.

9. Battistoni A, Rubattu S, Volpe M. Circulating biomarkers with preventive, diagnostic and prognostic implications in cardiovascular diseases. Int J Cardiol 2012;157 (2): 160-8.

10. Taglieri N, Fernandez-Berges DJ, Koenig W, et al. Plasma cystatin C for prediction of 1 -year cardiac events in Mediterranean patients with non-ST elevation acute coronary syndrome. Atherosclerosis 2010;209 (1):300-5.

11. European Heart Rhythm Association; European Association for Cardio-Thoracic Surgery, Camm AJ, et al. Guidelines for the management of atrial fibrillation: the Task Force for the Management of Atrial Fibrillation of the European Society of Cardiology (ESC). Eur Heart $J$ 2010;31 (19):2369-429
12. Taglieri N, Koenig W, Kaski JC. Cystatin C and cardiovascular risk. Clin Chem 2009;55 (11): 1932-43.

13. Alonso A, Lopez FL, Matsushita K, et al. Chronic kidney disease is associated with the incidence of atrial fibrillation: the Atherosclerosis Risk in Communities (ARIC) study. Circulation 2011;123 (25): 2946-53.

14. McManus DD, Corteville DC, Shlipak MG, et al. Relation of kidney function and albuminuria with atrial fibrillation (from the Heart and Soul Study). Am J Cardiol 2009;104:1551-5.

15. Soliman EZ, Prineas RJ, Go AS, et al. Chronic kidney disease and prevalent atrial fibrillation: the Chronic Renal Insufficiency Cohort (CRIC). Am Heart J 2010;15 (6):1102-7.

16. Targoński R, Salczyńska D, Sadowski J, et al. Relationship between inflammatory markers and clinical patterns of atrial fibrillation in patients with congestive heart failure. Kardiol Pol 2008; 66 (7):729-36.

17. Yap YG. Inflammation and atrial fibrillation: cause or para-phenomenon? Europace 2009;11 (8): $980-1$.

18. Conen D, Ridker PM, Everett BM, et al. A multimarker approach to assess the influence of inflammation on the incidence of atrial fibrillation in women. Eur Heart $\mathrm{J} 2010 ; 31$ (14):1730-6.

19. Rienstra M, Sun JX, Magnani JW, et al. White blood cell count and risk of incident atrial fibrillation (from the Framingham Heart Study). Am J Cardiol 2012;109 (4):533-7.

20. Qing $X$, Furong $W$, Yunxia $L$, et al. Cystatin $C$ and asymptomatic coronary artery disease in patients with metabolicsyndrome and normal glomerular filtration rate. Cardiovasc Diabetol. 2012;11:108.

21. Linssen GC, Rienstra M, Jaarsma T, et al. Clinical and prognostic effects of atrial fibrillation in heart failure patients with reduced and preserved left ventricular ejection fraction. Eur $\mathrm{J}$ Heart Fail 2011;13 (10):1111-20. 